IZA DP No. 10324

Entrepreneurship in the Shadows:

Wealth Constraints and Government Policy

Semih Tumen

October 2016 


\title{
Entrepreneurship in the Shadows: Wealth Constraints and Government Policy
}

\author{
Semih Tumen \\ Central Bank of the Republic of Turkey, \\ IZA and ERF
}

Discussion Paper No. 10324

October 2016

\author{
IZA \\ P.O. Box 7240 \\ 53072 Bonn \\ Germany \\ Phone: +49-228-3894-0 \\ Fax: +49-228-3894-180 \\ E-mail: iza@iza.org
}

Any opinions expressed here are those of the author(s) and not those of IZA. Research published in this series may include views on policy, but the institute itself takes no institutional policy positions. The IZA research network is committed to the IZA Guiding Principles of Research Integrity.

The Institute for the Study of Labor (IZA) in Bonn is a local and virtual international research center and a place of communication between science, politics and business. IZA is an independent nonprofit organization supported by Deutsche Post Foundation. The center is associated with the University of Bonn and offers a stimulating research environment through its international network, workshops and conferences, data service, project support, research visits and doctoral program. IZA engages in (i) original and internationally competitive research in all fields of labor economics, (ii) development of policy concepts, and (iii) dissemination of research results and concepts to the interested public.

IZA Discussion Papers often represent preliminary work and are circulated to encourage discussion. Citation of such a paper should account for its provisional character. A revised version may be available directly from the author. 


\section{ABSTRACT \\ Entrepreneurship in the Shadows: Wealth Constraints and Government Policy ${ }^{*}$}

I develop a dynamic model of forward-looking entrepreneurs, who decide whether to operate in the formal economy or informal economy and choose how much to invest in their businesses, taking government policy as given. The government has access to two policy tools: taxes on formal business activity and enforcement (or policing) discouraging informality. The main focus of the paper is on transitional dynamics under different initial wealth levels. Whether an initially small business will be trapped in the informal economy and remain small forever or grow quickly and become a large formal business depends on tax and enforcement policies. High tax rates accompanied by loose enforcement - which is mostly the case in less-developed countries (LDCs) - induce tax avoidance, discourage investment in formal businesses, and drive the entrepreneurial activity toward the informal sector even though the initial wealth level is high. Lowering taxes on formal activity joined with strict enforcement can help reducing the magnitude of poverty traps in LDCs.

JEL Classification: E21, E26, L26, O17

Keywords: entrepreneurship, informal economy, government policy, investment, wealth constraints

Corresponding author:

Semih Tumen

Research and Monetary Policy Department

Central Bank of the Republic of Turkey

Istiklal Cad. No:10

06100 Ulus, Ankara

Turkey

E-mail: semih.tumen@tcmb.gov.tr

\footnotetext{
* I thank Tiago Cavalcanti, Enrique Martinez-Garcia, Jose Victor Rios-Rull, Mark Sanders, Orhan Torul, the participants of the Midwest Macroeconomics Meeting in Urbana, North American Summer Meeting of the Econometric Society in Los Angeles, and Econometric Society European Meeting in Gothenburg for useful suggestions. I am particularly grateful to Guido Friebel (the Editor) and two anonymous referees for their very helpful comments. The views expressed here are of my own and do not necessarily reflect those of the Central Bank of the Republic of Turkey. All errors are mine.
} 


\section{Introduction}

In the developing world, informality is quite prevalent among small businesses. Using survey data from Brazil, De Paula and Scheinkman (2011) document that around 80 percent of the small enterprises are not registered with Brazilian tax authorities. Moreover, informal entrepreneurs tend to invest in their businesses much less intensively than the formal ones, which implies that formality is positively correlated with asset size. ${ }^{1}$ Similar patterns can also be confirmed for other developing countries with large informal sectors [see Ayyagari, Beck, and Demirguc-Kunt (2007)].

Theory predicts that high taxes on formal economic activity and loose enforcement (or policing) drive the size of informal activity up in these countries. ${ }^{2}$ The empirical evidence is in agreement with this prediction. Both cross-country and country-level studies find that the size of informal sector tend to be large in countries with high tax rates and weak institutional arrangements. $^{3}$ The consensus is that the government should use a mix of tax and enforcement policies to effectively reduce the size of informal economy [Ihrig and Moe (2004)].

In this paper, I argue that wealth constraints interact with government policy to determine the share of informal entrepreneurial activity in the economy. Specifically, I show that, given an initial wealth level, whether a small business will be trapped in the informal economy and stay small forever or grow quickly and establish itself as a large formal business depends on how the government combines tax and enforcement policies. When the tax rates are extremely high and enforcement is very loose, the extent of tax avoidance will be extensive. Entrepreneurs with small initial wealth levels will be trapped in the informal sector forever and the incentives to invest in physical assets will be low. Even the unconstrained entrepreneurs (i.e., the initially wealthy ones), who initially operate formally, may tend to downsize and

\footnotetext{
${ }^{1}$ Based on the information provided by SEBRAE (Brazilian Small Business Administration), small businesses account for around 94 percent of all firms. Informal small businesses hold around 15-20 percent of the assets held by all small businesses in the Brazilian economy. Thus, the data suggest that informal small businesses tend to be much smaller than the formal ones. See De Paula and Scheinkman (2011) for more detailed descriptive statistics on formal and informal small businesses in Brazil. Throughout the paper, "size" of a small business means the "asset size."

${ }^{2}$ See, for example, Loayza (1996), Ihrig and Moe (2004), and Tumen (2016).

${ }^{3}$ Papers in this literature include Johnson, Kaufmann, and Zoido-Lobaton (1998), Schneider and Enste (2000), and Schneider, Buehn, and Montenegro (2010). Note that some papers [e.g., Friedman, Johnson, Kaufmann, and Zoido-Lobaton (2000)] find that the unconditional correlation between taxes and the size of informal economy can be negative; but, this negative correlation tends to turn to positive once institutional arrangements (such as enforcement and measures to combat corruption) are controlled for.
} 
switch to informality in the long run. Suppose that the government starts decreasing taxes and tightening enforcement. At the beginning, the unconstrained entrepreneurs will exhibit a behavioral change: they will invest in their businesses, start growing, and stay in the formal sector forever. There will still be many small businesses trapped in the informal economy. But, at least, informal and formal businesses coexist in the long run. When the taxes are reduced sufficiently and enforcement is tightened further, even those informal entrepreneurs with very low initial wealth levels may choose to grow aggressively and establish a permanent presence in the formal economy.

The theoretical framework features a fundamental non-convexity that leads to a dual structure in the economy: the entrepreneurs operate either in the formal economy or in the informal economy. On the one hand, operating in the formal economy is attractive because a unit of physical asset produces a larger amount of output in the formal economy [Thomas (1992)]. Formal activity is more costly, on the other hand, because a formal business should register with the official tax system, but the informal business pays the tax only if it is caught. As a result, the entrepreneur faces a cost-benefit tradeoff on the margin of formality versus informality. This margin is the source of the fundamental non-convexity. It is well-known that such non-convexities pave the way for poverty traps in economic models. ${ }^{4}$

In this paper, the term "poverty trap" is used to describe the extent of the "non-convergence" problem [see Azariadis (1996)]..$^{5}$ In standard models, a convergence path refers to the footsteps of the poor on the way to getting rich. However, this convergence path might be interrupted for several reasons leading the poor to stay poor for a long time. This paper suggests that the interactions between initial wealth levels and government policy might generate such an interruption. To be specific, if taxes on formal economic activity is too high and enforcement is loose, then initially wealth-constrained entrepreneurs might get trapped in the informal

\footnotetext{
${ }^{4}$ See Banerjee (2004) for an excellent review of the related literature. It is worthwhile to note that this type of non-convexities are sufficient but not necessary to generate poverty traps in economic models [Mookherjee and Raj (2002)].

${ }^{5}$ Note that there are also more objective/quantitative measures to define a poverty trap. For example, time series evolution of inequality measures (i.e., the Gini index) may be used to quantify the persistence of inequality in a country and, therefore, may be proposed as an objective measure of poverty traps. It is also possible to construct ratios of consumption on the upper versus lower portions of the income distribution and link the persistence of this measure to poverty traps. Another approach might be to compare the labor income processes of the poor and the rich to identify the factors that might lead to persistent differences in long-run income and use those factors as objective measures of poverty traps.
} 
economy and stay small forever. The "magnitude" of the poverty trap is higher if a larger fraction of the entrepreneurs are trapped in the informal sector. ${ }^{6}$ The mechanics of poverty trap developed in this paper are similar to the ones offered by papers including Galor and Ryder (1989), Murphy, Shleifer, and Vishny (1989), and Durlauf (1993). This literature suggests that differences in initial conditions - determined by history and inheritance - might lead to non-convergence. Different from this literature, I say that government policy may also contribute to convergence (or non-convergence) experiences and, therefore, affect the magnitude of poverty traps.

The main contribution of this paper is the idea that the government, by setting high tax rates on formal activity and imposing loose enforcement, can itself cause large and persistent poverty traps. There are other theoretical papers in the literature - see, for example, Ihrig and Moe (2004) - arguing that high tax rates joined with weak enforcement can inflate the scale of informal activity. My paper is different from these models in two main respects. First, the models in the literature typically compare the steady state outcomes under different government policy scenarios, whereas the model I develop is capable of producing analytically tractable transitional dynamics. Using the transitional dynamics exercise, one can test the role of government policy on transitions from informality to formality or vice versa. Second, the steady state outcomes in this literature - as in Ihrig and Moe (2004) - feature either an entirely informal economy or an entirely formal economy depending on taxes and enforcement. The model I develop allows for the possibility of multiple equilibria in which informal and formal entrepreneurs can coexist in the long run. These two aspects together allow for studying the potential interactions between government policy and the magnitude of poverty traps in developing economies.

Although the choice of formality versus informality is a static problem, the model is built on a basic dynamic equilibrium framework, in which the entrepreneur chooses how much to consume and how much to invest in physical capital at each time period. In terms of the modeling practices, the model is most closely related to Buera (2008). Similar to Buera (2008),

\footnotetext{
${ }^{6}$ See McKenzie and Woodruff (2006) for a similar definition and related literature review.
} 
I show that initial wealth positions determine both the transitional dynamics and steady-state outcomes of individuals. Different from Buera's model, I focus on the informal versus formal sector choice, since the main purpose of the present study is to understand the effect of government policy on the formal/informal decision margin. Another closely related paper is De Paula and Scheinkman (2011), who construct a static model to differentiate the informalformal margin using the differences in the cost of financing. Unlike their work, I specify a fully dynamic model and focus on transitional dynamics to understand how government policy mediates the correlation between initial wealth constraints and informal versus formal entrepreneurship. The benchmark model assumes that the entrepreneurs have no other income besides their revenue. They run their businesses by choosing the optimal level of assets to employ, while labor is assumed away for simplicity. Different types of taxes that the entrepreneur faces are represented by a single tax rate. The entrepreneurs live in a world with perfect certainty. And, finally, the tax revenues are subject to wasteful spending. I argue that relaxing these simplifying assumptions does not alter the qualitative predictions of the benchmark model significantly [see Section 4].

This paper is also related to the growing body of literature on the link between entrepreneurship and wealth constraints. A particular strand of this literature argues that wealth constraints are important determinants of entrepreneurship [see, e.g., Evans and Jovanovic (1989), Holtz-Eakin, Joulfaian, and Rosen (1994), Blanchflower and Oswald (1998), Lindh and Ohlsson (1998), and Gentry and Hubbard (2004)]. ${ }^{7}$ I argue that wealth constraints also bind for the intensive margin of entrepreneurial choice (i.e., choosing whether to operate as an informal or formal entrepreneur), rather than only the extensive margin. I also argue that the degree to which the wealth constraints bind is a function of the tax and enforcement policies, which is a novel idea in the literature.

It is also possible to link this paper to the literature investigating how entrepreneurial saving or investment behavior is affected by government policy. For example, Fossen and Rostam-

\footnotetext{
${ }^{7}$ Whether the correlation between wealth constraints and the probability of becoming an entrepreneur is spurious or not is a controversial issue. See de Meza and Southey (1996), de Meza (2002), Hurst and Lusardi (2004), Nanda (2010), and Kerr and Nanda (2011) for a review of the relevant issues in this literature.
} 
Afschar (2012) argue that changes in government policy that entail greater income uncertainty may lead to changes in the saving behavior of entrepreneurs via shifting both the amount and the composition of their savings. Cullen and Gordon (2007) show using the U.S. data that the entrepreneurial risk-taking behavior responds different forms of tax/incentive policies in differing degrees. ${ }^{8}$ Peck (1989) argues that the design of tax policy can play important roles for smoothing out the negative effects of market imperfections on the profits of small businesses. Boadway, Marchand, and Pestieau (1991) derive an optimal linear tax formula and study how it interacts with entrepreneurial choices. Similar to these papers, I also link government policy to entrepreneurs' choices and outcomes. Different from them, I focus on the formal/informal margin, and show how the interactions between initial wealth constraints and government policy determine long-run fractions of formal and informal entrepreneurs in an economy.

Although the current paper mostly adopts a developing country perspective, the link between entrepreneurship and economic growth is a source of major debate also in developed countries. The slowdown in global economic growth rates, which became more evident following the 2008 financial crisis, is often argued as being a consequence of the slowdown in productivity growth. There are several studies, including Haltiwanger, Jarmin, and Miranda (2013), Decker, Haltiwanger, Jarmin, and Miranda (2014), and IMF (2016), linking productivity growth to entrepreneurship. So, the observed slowdown in business start-up rates in major economies, including the U.S., Canada, and many European countries, is seen as a major reason behind the decline in global growth rates. For example, Haltiwanger (2012) documents that around 20 percent of the U.S. gross job creation can be attributed to business start-ups. The picture in developing economies is somewhat different. Schoar (2010) and Hsieh and Klenow (2014) show that there are too many entries in developing countries, which results in too many subsistence (and potentially informal) entrepreneurs. As Decker, Haltiwanger, Jarmin, and Miranda (2014) argue, the common element in these two examples is the lack of high-growth transformational entrepreneurs. This paper shows that government policy in the form of tax and enforcement incentives has a potential to increase the share of

\footnotetext{
${ }^{8}$ See also Kanbur (1981) for a general equilibrium model investigating the implications of government policy for entrepreneurial risk taking.
} 
transformational entrepreneurs and spur economic growth, which applies to both developing and developed economies. ${ }^{9}$

Finally, it will perhaps be useful to discuss from a broader perspective the position of the current paper within the informality literature. Informal businesses are analyzed in the literature along three different frameworks [La Porta and Shleifer (2008, 2014), Jones (2008)]. The first is called the "romantic view" and it suggests that informal businesses are not less productive/efficient than the formal businesses. According to this view, the informal activity is held back by government through high taxes, strict enforcement, and weak intellectual property rights [see, e.g., De Soto $(1989,2000)]$. The key assumption, which is often criticized as being over-optimistic, is that informal businesses are similar to formal ones, but their activity is kept down by policy. The second is called the "parasitic view" and is less optimistic than the romantic view. It basically says that unofficial businesses are much less productive than their official counterparts and they are owned by less skilled entrepreneurs; thus, to stay alive, they need to stay small and cut their prices, which harms the official productive businesses and erodes their growth potential [see, e.g., Farrell (2004)]. The third is called the "dualistic view," which assumes that the economy is characterized within a dual structure that sorts less skilled entrepreneurs to small and informal businesses and more skilled ones to large and formal businesses [see, e.g., Rauch (1991) and Amaral and Quintin (2006)]. Along the development path, productive resources increase and the share of formal activity goes up over time. Eventually, the developed economy emerges with only a tiny share of informal activity. Based on this view, the government can intervene to speed up the transition process. This paper perfectly fits into the dualistic view and argues that government policy can increase the speed of development through several channels. Our results on poverty traps are also consistent with this view.

The plan of the paper is as follows. Section 2 presents the benchmark model and outlines the solution method. Section 3 provides an extensive discussion of the transitional dynamics in the benchmark economy. How the transitional dynamics respond to changes in government

\footnotetext{
${ }^{9}$ For other breakthrough papers linking entrepreneurship to tax policy, see Gordon (1998), Hubbard and Gentry (2000), and Hubbard and Gentry (2005).
} 
policy is also discussed in depth. Section 4 sketches several extensions of the benchmark model and argues how the predictions of the benchmark model could change upon relaxing its main assumptions. Section 5 concludes.

\section{The Benchmark Model}

Time is continuous and indexed by $t \geq 0$. At each point in time, the entrepreneur has the option to operate in the formal economy or informal economy. He holds physical assets $a$ and fully invests these assets into his business to produce output. Moreover, he chooses the level of investment each period and add the invested amount over the stock of physical assets to be used in production in the next period. The initial level of physical assets, $a(0)$, is endowed to the entrepreneur. Borrowing or lending is not allowed.

The government designs tax and enforcement policies to encourage formal economic activity. Specifically, the government sets a tax rate as a fraction $\tau \in[0,1]$ of entrepreneurial output. The formal entrepreneur pays this fraction fully, but the informal entrepreneur pays it only if he is caught. The probability of getting caught is described by $\phi \in[0,1] .{ }^{10}$ This is called the enforcement (or policing) parameter. Thus, each period the informal entrepreneur expects to pay the tax $\phi \tau$, which means that he pays the tax conditional on getting caught. This policy setup is similar to Ihrig and Moe (2004) and Tumen (2016).

\section{$2.1 \quad$ Preferences}

The entrepreneur's preferences over consumption profiles are defined by the following utility specification:

$$
U(c)=\int_{0}^{\infty} e^{-\rho t} \frac{c(t)^{1-\sigma}}{1-\sigma} d t
$$

\footnotetext{
${ }^{10}$ In the benchmark model, the parameter $\phi$ is assumed to be fixed, which means that each entrepreneur has an equal and constant probability of getting caught by the police in the case of informal operation. But, in reality, larger businesses are much more visible and the probability of getting caught goes up with the asset size. To obtain an analytically solvable dynamic system, I assume that $\phi$ is fixed. But, this is relaxed later in the paper [see Section 4.1] and an extensive discussion is provided to emphasize that having $\phi$ as an increasing function of the asset size does not alter the qualitative nature of the results obtained from the benchmark model.
} 
where $\rho$ is the rate of time preference and $\sigma$ is the reciprocal of the intertemporal elasticity of substitution. The constant relative risk aversion (CRRA) specification ensures that the period utility over consumption is strictly increasing and strictly concave. It is also possible to attribute a life-cycle interpretation to this setup. Under this interpretation, $\rho=\rho^{*}+d$, where $\rho^{*}$ is the rate of time preference and $d$ is the constant rate of death for the entrepreneur. For notational simplicity, I will abstract from life-cycle considerations and use $\rho$ as the rate of time preference.

\subsection{Technology and Constraints}

At any point in time, the physical assets of the individual entrepreneur evolve according to the law of motion

$$
\dot{a}(t)=\mathcal{Y}(a(t))-c(t)
$$

for all $t \geq 0$ and given an initial asset level $a(0)>0$. The notation $\dot{a}$ refers to the time derivative. Depreciation is assumed away. The function $\mathcal{Y}$ describes the net-of-tax entrepreneurial revenue and is formulated as follows:

$$
\mathcal{Y}(a(t))=\left\{\begin{array}{cl}
\theta a(t)^{\alpha_{f}}(1-\tau)-s, & \text { if operates formally, } \\
\theta a(t)^{\alpha_{i}}(1-\phi \tau), & \text { if operates informally }
\end{array}\right.
$$

where $0<\alpha_{f}<1$ is the returns to scale parameter in the formal economy, $0<\alpha_{i}<1$ is the returns to scale parameter in the informal economy, $s>0$ is a constant social security contribution by the formal entrepreneur, and $\theta>0$ is a fixed technology shifter. ${ }^{11}$ Note that the production function $\theta a(t)^{\alpha_{k}}, k=f, i$, is strictly increasing in $a(t)$ and satisfies the standard Inada conditions. To capture the fact that production in the formal economy is more capital intensive than that in the informal economy, I assume $\alpha_{f}>\alpha_{i}$. This assumption makes formal economy more attractive, because one unit of the physical asset produces a larger amount of output in the formal economy than in the informal economy everything else equal. This implies

\footnotetext{
${ }^{11}$ Imposing the assumption $s>0$ only implies that the entrepreneur chooses to stay informal at very low asset levels. However, it is possible to set the social security contribution $s$ to be equal to zero without affecting any of the results qualitatively. For simplicity, I ignore any potential future benefits of current social security contributions to the formal entrepreneur. So, in the current setup, $s$ serves only as an arbitrary fixed cost.
} 
that the entrepreneur's sectoral choice problem is subject to a fundamental tradeoff: whether to operate in the more productive formal economy or in the less costly (due to lower taxes) in the informal economy. ${ }^{12}$ Note that this assumption is not critical and can be relaxed without changing the main predictions of the benchmark model qualitatively [see Section 4.2].

\subsection{Sectoral Choice}

The sectoral choice problem of the entrepreneur is a static one. Given the physical asset level $a(t)$, the entrepreneur decides at each instant whether to operate in the formal economy or in the informal economy based on the following choice rule:

$$
\max \left\{\theta a(t)^{\alpha_{f}}(1-\tau)-s, \theta a(t)^{\alpha_{i}}(1-\phi \tau)\right\}
$$

There exists a threshold level $a_{T}$, which is time independent, making the entrepreneur indifferent between operating in the formal versus informal economy. Formally, this threshold satisfies the following condition:

$$
\theta a_{T}^{\alpha_{f}}(1-\tau)-s=\theta a_{T}^{\alpha_{i}}(1-\phi \tau)
$$

At any instant $t \geq 0$, the entrepreneur operates in the formal economy if $a(t)>a_{T}$ and he operates his business in the informal economy if $a(t) \leq a_{T}$. This defines the optimal sectoral decision. Figure (1) visually describes the threshold-crossing behavior.

Notice that the threshold physical asset level $a_{T}$ can be redefined as the implicit function $a_{T}\left(\tau, \phi, s, \alpha_{f}, \alpha_{i}\right)$; that is, the threshold separating formality from informality is a function of tax/enforcement policies, technology, and the social security contribution. Throughout this section, I assume that $\alpha_{f}>\alpha_{i}$ and I will take those parameters fixed. Similarly, I treat

\footnotetext{
${ }^{12}$ The assumption that formal sector is more productive than the informal sector, e.g., $\alpha_{f}>\alpha_{i}$, has an empirical background. One can think of various reasons that may lead to this productivity gap. First, informal businesses tend to stay small to reduce the probability of getting caught. This may lead to a failure to achieve the economies of scale and the associated decline in marginal costs. For example, WorldBank (2005) documents that a percentage point increase in the share of informal employees in a firm is associated with a 0.3 percent decline in factor productivity. Second, and related to the first, the tendency to stay small leads the small informal businesses to hire low-skill workers, which may reduce productivity further [McKinsey (1998)]. Third, the organizational design is more inefficient in informal businesses. Fourth, access to governmental resources and legal services are highly restricted in the informal sector. Finally, these limited access may lead to a greater incentive for intra-organizational corruption.
} 


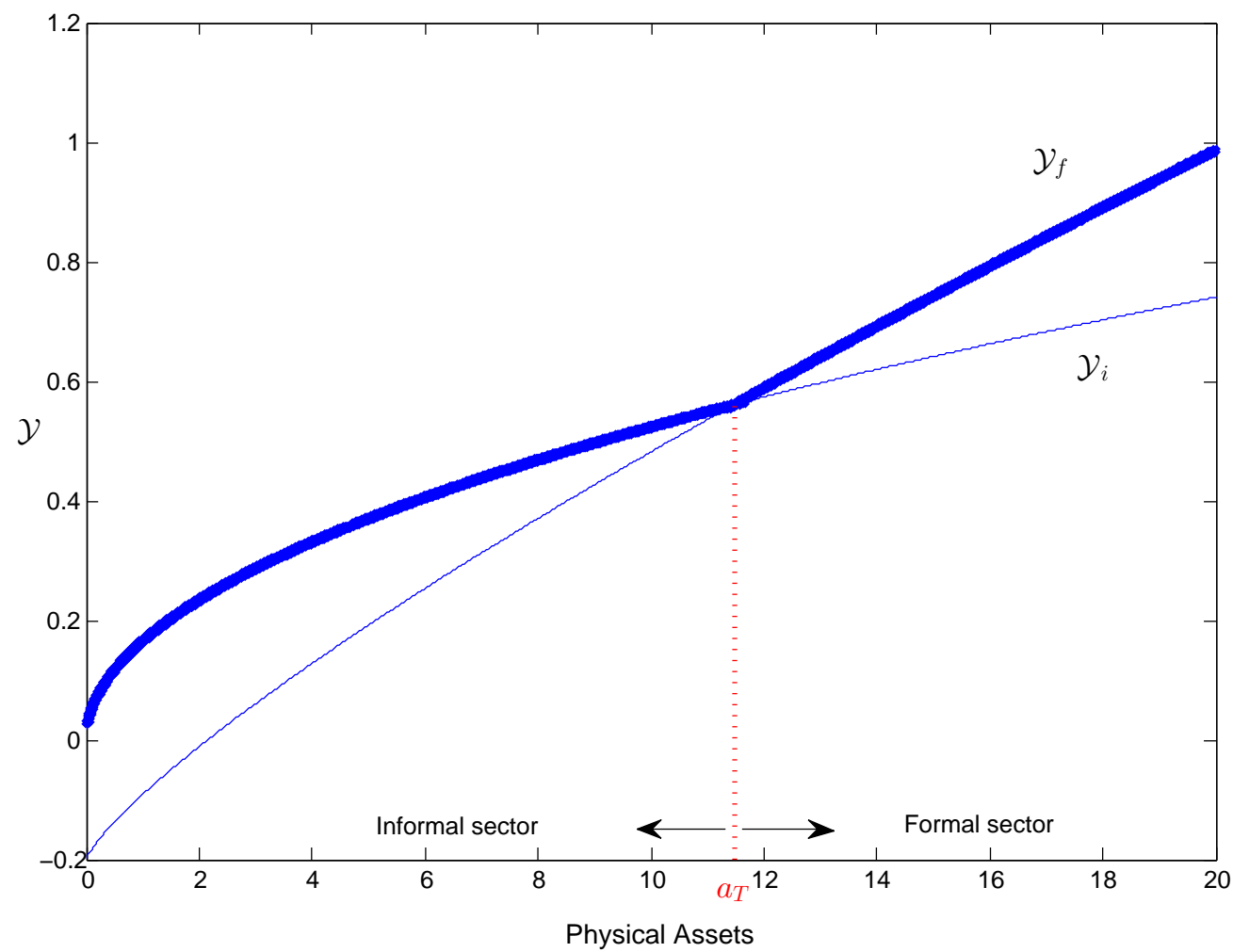

Figure 1: Sectoral choice - The figure plots $\mathcal{Y}$ versus $a$. The asset level where $\mathcal{Y}_{f}$ and $\mathcal{Y}_{i}$ crosses is the threshold level, $a_{T}$. The entrepreneur operates informally when $a \leq a_{T}$, while he operates formally when $a>a_{T}$. In this particular example, $\rho=0.05, \tau=0.4, \phi=0.2, s=0.2, \theta=0.18, \alpha_{f}=0.8$, and $\alpha_{i}=0.6$.

the technology shifter $\theta$ also as a constant. The potential consequences of relaxing these assumptions will be discussed in Section 4 .

The effect of the social security contribution is easy to grasp. It shifts the formal net output $\mathcal{Y}_{f}$ up and down keeping $\mathcal{Y}_{i}$ unaltered. To be precise, an increase in $s$ shifts $\mathcal{Y}_{f}$ down, which pushes $a_{T}$ up. This suggests that a higher social security contribution discourages formal entrepreneurship and raises the share of informal activity. As a result, $\partial a_{T} / \partial s>0$.

The main focus of this paper is on the effects of tax and enforcement policies on formal versus informal entrepreneurship. I perform several policy experiments to understand the interactions between government policy and the threshold asset level, $a_{T}$. I first vary the level of taxes. To see what happens, I totally differentiate Equation (2.5) with respect to $a_{T}$ and $\tau$ holding 
everything else constant. This exercise yields the expression

$$
\frac{d a_{T}}{d \tau}=\frac{a_{T}^{\alpha_{f}}-\phi a_{T}^{\alpha_{i}}}{\alpha_{f} a_{T}^{\alpha_{f}-1}(1-\tau)-\alpha_{i} a_{T}^{\alpha_{i}-1}(1-\phi \tau)}>0,
$$

which means that higher tax rates (everything else constant) increase the asset threshold, discourage formal activity, and induce tax avoidance. The numerator is clearly positive. After some algebra, it is also clear that the denominator is also positive. In other words, higher tax rates are associated with larger physical asset requirements to operate in the formal economy. Notice that this derivative is a function of the enforcement rate. The effect of taxes on the threshold asset level $a_{T}$ will get smaller as the enforcement rate $\phi$ goes up. This means that the policy strategy of reducing taxes to discourage informality will be more effective in environments with weak enforcement.

Now I vary the enforcement parameter, which gives

$$
\frac{d a_{T}}{d \phi}=\frac{-\tau a_{T}^{\alpha_{i}}}{\alpha_{f} a_{T}^{\alpha_{f}-1}(1-\tau)-\alpha_{i} a_{T}^{\alpha_{i}-1}(1-\phi \tau)}<0 .
$$

This suggests that increasing the intensity of policing in the economy reduces the asset threshold, generating a switch from informal activity toward formality. The derivative of $a_{T}$ with respect to $\phi$ is a decreasing function of $\tau$, meaning that strong enforcement will be more efficient in low tax environments. To summarize, high taxes combined with loose policing strongly discourage formality, while low taxes with strong enforcement reduce tax avoidance and increase formal participation. Notice that lowering taxes in an environment with loose policing will be an inefficient policy move. Similarly, strengthening enforcement in an environment with high tax rates will again be inefficient. This framework suggests that the best policy option is to strengthen enforcement while reducing taxes.

It will perhaps be useful to reemphasize the main insights gained in this static model. This model implicitly defines the sectoral choice problem of the entrepreneur as a function of government policy. Lowering taxes and tightening enforcement measures can reduce the share of informal entrepreneurship. The reason is that lower taxes reduce the cost of formality and 
stricter regulation makes it harder to lurk in the shadows. However, the key components of this problem, which are missing in the static sectoral choice decision, are asset accumulation and the associated initial wealth constraints. These components determine whether a small informal entrepreneur can end up in the formal economy in the long-run equilibrium or not. The next subsection introduces the asset accumulation problem and describes the solution of the fully dynamic system. This setup will enable us to understand the effect of wealth constraints on sectoral entrepreneurial allocation and to examine how government policy diffuses into this relationship.

\subsection{The Optimization Problem}

The entrepreneur makes three choices: consumption, physical assets (i.e., investment), and whether to operate in the formal versus informal economy. Formally, the entrepreneurs solves the problem

$$
\begin{aligned}
\max _{c(t), a(t) \geq 0} & \int_{0}^{\infty} e^{-\rho t} \frac{c(t)^{1-\sigma}}{1-\sigma} d t \\
& \text { subject to } \\
& \dot{a}(t)=\mathcal{Y}(a(t))-c(t), \\
& \mathcal{Y}(a(t))=\max \left\{\mathcal{Y}_{f}(a(t)), \mathcal{Y}_{i}(a(t))\right\},
\end{aligned}
$$

given $a(0)>0$. The full solution to the static sectoral choice problem is described in detail in the previous subsection. Taking as given government policy, the dynamic problem of choosing optimal sequences of consumption and physical assets can be solved by constructing the following current-value Hamiltonian:

$$
\mathcal{H}(a, \lambda, c, t)=\frac{c^{1-\sigma}}{1-\sigma}+\lambda[\mathcal{Y}(a)-c]
$$

where $\lambda$ is the shadow price (or the co-state variable) used to value increments to physical assets. To simplify the notation, I drop the time index in what follows. The first-order 
condition with respect to consumption is simply

$$
c^{-\sigma}=\lambda
$$

The shadow price evolves according to the law of motion

$$
\dot{\lambda}= \begin{cases}\rho \lambda-\lambda \alpha_{f} \theta a^{\alpha_{f}-1}(1-\tau), & \text { if operates formally (i.e., } \left.a>a_{T}\right) \\ \rho \lambda-\lambda \alpha_{i} \theta a^{\alpha_{i}-1}(1-\phi \tau), & \text { if operates informally (i.e., } \left.a \leq a_{T}\right)\end{cases}
$$

where the decision to operate formally versus informally is determined by the simple threshold $a_{T}$. Using this law of motion for the co-state variable joined with the first-order condition (2.8), the Euler equation (or the growth rate of consumption) can be formulated as

$$
\frac{\dot{c}}{c}= \begin{cases}{\left[\alpha_{f} \theta a^{\alpha_{f}-1}(1-\tau)-\rho\right] / \sigma,} & \text { if } a>a_{T}, \\ {\left[\alpha_{i} \theta a^{\alpha_{i}-1}(1-\phi \tau)-\rho\right] / \sigma,} & \text { if } a \leq a_{T} .\end{cases}
$$

Finally, to guarantee convergence in the dynamic model, the following transversality condition needs to be satisfied:

$$
\lim _{T \rightarrow \infty} \int_{0}^{T} e^{-\rho t} \lambda(t) a(t) d t=0
$$

This solution suggests that there are two different consumption and asset accumulation patterns in the economy: one for the formal entrepreneurs and the other for the informal entrepreneurs. The steady-state levels of consumption and physical assets can easily be solved analytically. I am interested in a particular solution, in which $\dot{c}=0$ and $\dot{a}=0$. In the formal economy, the steady-state levels of consumption and physical assets are

$$
c_{s s}^{f}=\theta(1-\tau)\left[\frac{\rho}{\alpha_{f} \theta(1-\tau)}\right]^{\alpha_{f} /\left(\alpha_{f}-1\right)}-s, \quad a_{s s}^{f}=\left[\frac{\rho}{\alpha_{f} \theta(1-\tau)}\right]^{1 /\left(\alpha_{f}-1\right)}
$$

respectively. In the informal economy, these quantities can be expressed in a similar manner 


$$
c_{s s}^{i}=\theta(1-\phi \tau)\left[\frac{\rho}{\alpha_{i} \theta(1-\phi \tau)}\right]^{\alpha_{i} /\left(\alpha_{i}-1\right)}, a_{s s}^{i}=\left[\frac{\rho}{\alpha_{i} \theta(1-\phi \tau)}\right]^{1 /\left(\alpha_{i}-1\right)} .
$$

Next I study transitional dynamics in this economy. The non-convexities due to sectoral choice problem generate a potential for multiple stable equilibria at the steady state. The government policy will determine the number and nature of these equilibrium solutions.

\section{Transitional Dynamics and Government Policy}

This section characterizes the co-evolution of consumption and physical asset levels, given initial conditions on individual wealth. From now on, it makes sense to assume that entrepreneurs are heterogeneous in terms of the initial asset levels they hold. In case of multiple equilibria (one for formal activity and the other for informal activity), these initial positions will determine which equilibrium the entrepreneur converges to. Following the convention in the analysis of dynamic models in continuous time, I will proceed with a description of the transitional dynamics using a standard phase diagram over the two-dimensional asset-consumption $(a-c)$ space.

Two equations describe the optimal trajectories. The first equation sets $\dot{c}=0$ in Equation (2.11), e.g., in the Euler equation. This equation (i.e., the $\dot{c}=0$ locus) is a vertical line crossing the $x$-axis at the steady state asset level. On the right of this vertical line, consumption is decreasing and it is increasing on the left. The second equation sets $\dot{a}=0$ in Equation (2.2), e.g., in the law of motion for the accumulation of physical assets. This equation gives us a set of points over which the consumption equals output minus investment at the steady state. Above this line, asset accumulation is negative and it is positive below.

Figure (2) exemplifies a case in which there are multiple stable equilibria and separate transitional dynamics that operate below and above the asset threshold $a_{T}$. In this particular example, there are multiple stable equilibria: one for informal activity (the left of $a_{T}$ ) and the other for formal activity (the right of $a_{T}$ ). One of this equilibria is reached conditional 


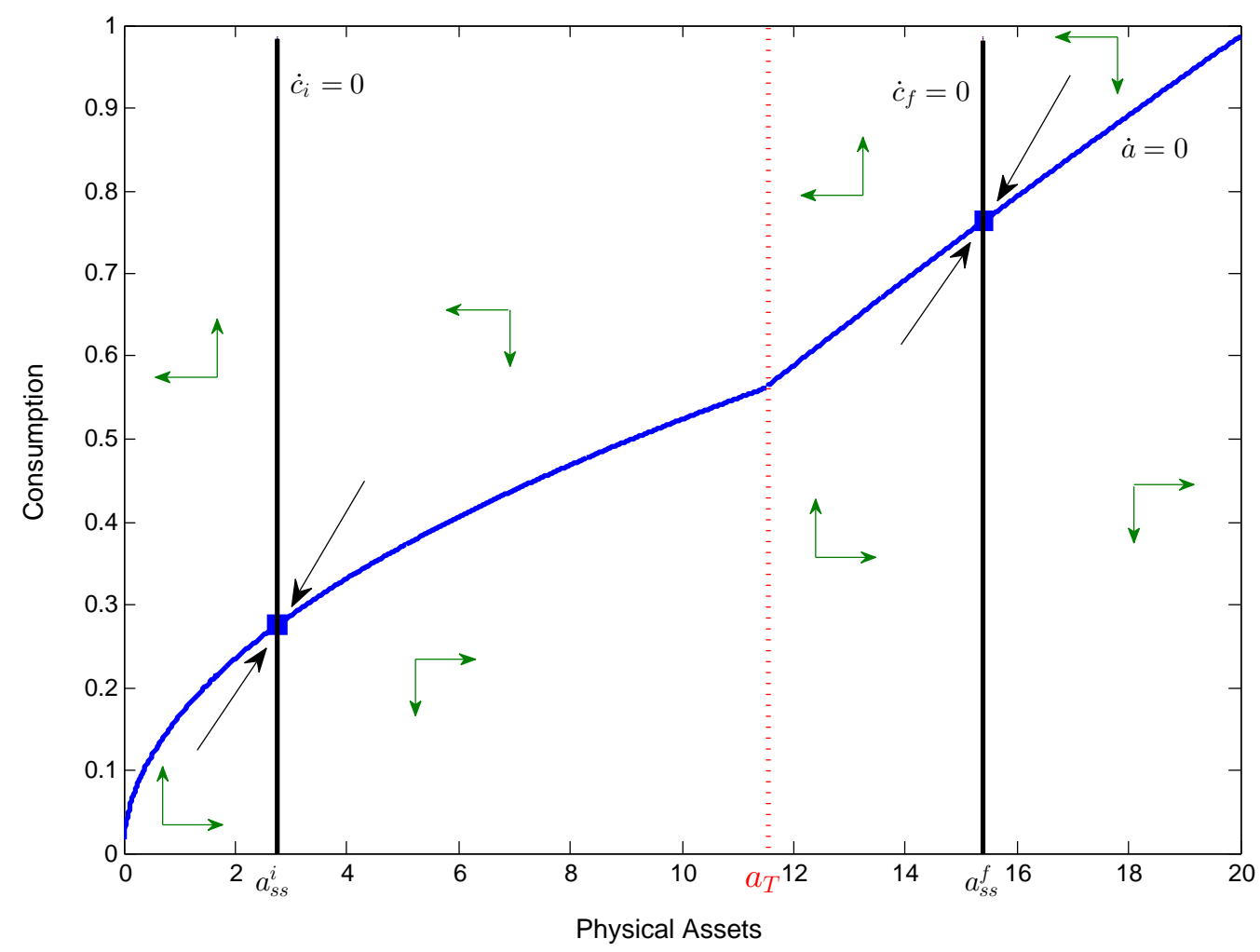

Figure 2: Optimal TRAJECTORIES - The figure plots optimal trajectories over the asset-consumption positive orthant. This particular example captures a case with multiple long-run equilibria.

on the initial asset position $a(0)$. This example says that if the entrepreneur starts in the formal economy, he stays in the formal economy forever and transitions toward the steady state position $\left(a_{s s}^{f}, c_{s s}^{f}\right)$. If, on the other hand, he starts in the informal economy, he will be trapped in the informal economy forever and will transition toward the point $\left(a_{s s}^{i}, c_{s s}^{i}\right)$. Note that $a_{s s}^{i}<a_{s s}^{f}$ and $c_{s s}^{i}<c_{s s}^{f}$, which suggest that those entrepreneurs who are trapped in informality will be of smaller size and will experience lower welfare levels than the formal entrepreneurs. Theoretically, there is no chance for them to change status and become formal prosperous entrepreneurs.

This paper argues that whether a case like Figure (2) describes will be observed or not depends on government policy. In the rest of this section, I will vary the policy parameters $\tau$ and $\phi$ to see how government policy affects transitional dynamics and how it determines the magnitude of poverty traps. The other parameters will not be altered throughout. To be consistent with the numbers used to plot the Figure (2.1), I set $\rho=0.05, \theta=0.18, \alpha_{i}=0.6, \alpha_{f}=0.8$, and 
$s=0.2$. I would like to highlight one parametric restriction that is crucial for the results. To get sensible transitional dynamics, it has to be the case in this setup that both $\alpha_{i}<\alpha_{f}<1$. In other words, the decreasing returns assumption is needed to get convergence in the long-run.

The key parameters in this setup are $\alpha_{f}$ and $\alpha_{i}$. In the literature evaluating the effect of tax policies on entrepreneurship, this parameter generally appears as a single parameter $\alpha$, since the papers in this literature do not distinguish between formal and informal entrepreneurs. Several papers, including Quadrini (2000), Li (2002), Cooper and Haltiwanger (2006), and Cagetti and De Nardi (2009), estimate $\alpha$ to be in the range of 0.6 and 0.8 . So, I set $\alpha_{i}$ to be equal to the lower bound of this range and $\alpha_{f}$ to the upper bound. The choice of the time preference rate $\rho$ is standard [see Buera (2008)]. The SEBRAE figures, mentioned in Footnote 1, says that informal entrepreneurs hold around 15 to 20 percent of the assets hold by all entrepreneurs in Brazil. This means that the formal/informal sector asset ratio ranges from 4 to 5.7. Similarly, using the cross-country figures presented in Ayyagari, Beck, and Demirguc-Kunt (2007), I calculate the formal entrepreneurs' contribution to the economy to be around 6 times larger than that of the informal entrepreneurs in Latin American countries. Accordingly, the steady-state asset ratio $a_{f} / a_{i}$ is set to match 5.7 by setting $s=0.2$ and $\theta=0.18$. I would like to note that the predictions of the model is somewhat sensitive to the choice of $\alpha_{f}$ and $\alpha_{i}$, and, in particular, the gap between these two parameters. However, sensitivity to the choice of $\alpha$ is a standard problem in the literature and is not specific to the model presented here. The tax and enforcement parameters, $\tau$ and $\phi$, are the free parameters in the simulations.

Before discussing the results, I would like to stress the main insight that the model promotes. Let us start with the case in Figure (2)-i.e., the case with multiple stable equilibria in the long run. As we increase taxes (and/or weaken enforcement) the distance between $a_{s s}^{f}$ and $a_{T}$ will get smaller. In other words, the asset requirements to own a formal business will go up. As we keep increasing taxes, eventually the good equilibrium will disappear and all entrepreneurs will operate in the informal sector. As we decrease taxes (and/or tighten enforcement), however, the distance between $a_{s s}^{i}$ and $a_{T}$ will get smaller; that is, the asset 
requirements to operate a formal business will get smaller. For sufficiently low taxes, the bad equilibrium will disappear and all entrepreneurs will end up in the formal economy. Thus, the bottom line is that government policy determines the share of entrepreneurship in the formal versus informal economies. Most importantly, government policy will determine the magnitude of poverty traps (i.e., the share of entrepreneurs who are trapped in the informal economy forever - these individuals will hold a smaller amount of assets and consume less than the formal entrepreneurs at the steady state).

Case I: Multiple stable equilibria (poverty traps and inequality). The case for multiple stable equilibria is plotted in Figure (2). There are two equilibrium levels: one for formal activity and one for informal activity. Formal and informal production coexist in the long run. Whether the entrepreneur will end up in the formal sector or informal sector is determined by the interaction between the initial wealth position and government policy. If the entrepreneur starts with low wealth (i.e., initial asset level below the threshold $a_{T}$ ), then he will converge to the informal equilibrium point $\left(a_{s s}^{i}, c_{s s}^{i}\right)$. Whether he will grow or contract along his optimal trajectory depends on whether his starting asset level is below or above the steady state asset level $a_{s s}^{i}$. If, on the other hand, the entrepreneur starts with a high initial asset level (i.e., asset level above $a_{T}$ ), then he converges to the formal equilibrium point $\left(a_{s s}^{f}, c_{s s}^{f}\right)$. Again, whether he will grow or contract along the optimal trajectory depends on whether his starting asset level is below or above the steady state asset level $a_{s s}^{f}$.

Notice that there are two different equilibrium levels: one with higher consumption and asset stock (formal equilibrium) and the other for lower consumption and asset stock (informal equilibrium). This suggests that welfare is different in those two equilibria and, therefore, there is persistent inequality in the long run. ${ }^{13}$ The extent of this inequality and the magnitude of the entrepreneurs trapped into poverty (i.e., in the informal economy with low asset and consumption levels) depends on the interaction between wealth constraints and government policy.

\footnotetext{
${ }^{13}$ In this sense, the model yields similar results to a set of papers including Banerjee and Newman (1993), Benabou (1993), Galor and Zeira (1993), and Durlauf (1996).
} 
To understand how this interaction works, think of the entrepreneurs whose initial wealth levels just below the threshold level $a_{T}$. Formally, think of the entrepreneurs with initial asset levels $a_{T}-\epsilon$, where $\epsilon>0$ is arbitrarily small. Decreasing taxes on formal production and/or increasing enforcement leads to a decline in $a_{T}$ and let's assume that the size of the decline is equal to $\epsilon$. In this new environment, those entrepreneurs in the left- $\epsilon$ neighborhood of $a_{T}$ (who would normally converge to the bad equilibrium) would switch to the right of $a_{T}$; thus, they will now converge to the good equilibrium. In other words, government policy would lead to a reallocation of informal entrepreneurs to the formal economy. Those who switch will now accumulate higher assets and consume more. Note that the high equilibrium point will also shift to the right through the general equilibrium effects and, as a result, the aggregate welfare will improve in the economy. A further implication of this exercise is that decreasing the tax rate (or tightening enforcement) will reduce $a_{T}$, which means that the asset requirements to become a formal entrepreneur will be lower. This encourages entrepreneurship and leads to a faster rate of growth in the economy.

The following two extreme examples will help the reader to fully understand how the interactions between wealth constraints and government policy affect the magnitude of poverty traps in the economy.

Case II: Informal equilibrium (perfect poverty). Now suppose that the government increases the taxes on formal activity from $40 \%$ to $50 \%$ and everything else remains constant. The upper panel in Figure (3) describes what happens. There are still two equilibrium levels in the economy, but the formal equilibrium is unstable. Therefore, the unique stable equilibrium is the informal equilibrium. In other words, independent of the initial level of assets, all entrepreneurs (even the initially prosperous ones) will eventually operate in the informal economy. Although this is a rather unrealistic case, it provides a good example of how government policy itself can inflate the size of poverty traps in the economy.

To understand why the formal equilibrium is unstable, think of the static sectoral choice problem. The entrepreneur would operate in the informal economy if $a \leq a_{T}$. As a result, 
once the entrepreneur enters this region, he will immediately jump to the optimal trajectory that would lead him toward the bad equilibrium (even if he was initially on the one that led him toward the good equilibrium).

Case III: Formal equilibrium (no poverty). Suppose now that the government reduces the taxes on formal activity from $40 \%$ to $30 \%$ keeping everything else constant. The lower panel in Figure (3) describes the new equilibrium. Similar to Case II, there is only one stable long-run equilibrium; but, this time, it is the good equilibrium. Irrespective of the initial wealth levels, all entrepreneurs converge to the formal equilibrium. There is no poverty in the long-run. The informal ones who start in poverty can grow quickly and switch to formality, which would lead them to high asset and consumption levels at the steady state. This case is an example of how welfare can improve in the economy without reducing the taxes to very low levels.

The punchline after understanding these three cases is the following. Taxing formal activity may be required in developing countries for fiscal concerns and other concerns related to macro policy. However, setting very high tax rates along with loose enforcement can have several adverse effects. Most importantly, high taxes and loose enforcement would induce tax avoidance behavior and provide incentives for lurking in the informal sector. These incentives will be particularly strong for those with small initial asset levels (i.e., those who are wealth constrained). High taxes and loose enforcement would also have long-run consequences in the benchmark setup. Given that poverty traps are defined as "non-convergence" (and, thus, measure poverty traps with the long-run fraction of informal entrepreneurs in the economy), these policies might lead to an increase in the magnitude of poverty traps in the long term. In such an environment, the asset, consumption, and production levels can be low. Overall, the benchmark model predicts that the interactions between initial wealth constraints and government policy can determine the level of long-run development in the economy. However, the benchmark model makes several assumptions and some of these assumptions may be strong. In the next section, I relax these assumptions in various directions and examine if the predictions of the benchmark model change. 
Before presenting the extensions, it will be useful to discuss the empirical implications of the theoretical predictions described above. Hsieh and Klenow (2014) provide a detailed comparison of the business performances in the U.S., India, and Mexico. They document that, in the U.S., firms of age 40 are, on average, 8 times larger than the firms of age 5 and below. In Mexico, firms of age 25 are twice as large as the new plants, but there is no difference between the 25 and 40 year-old firms. In India, they clearly document that old firms are no larger than the new ones. Moreover, informality is extensive in Mexico and India, while it is almost zero in the U.S. Informal plants in Mexico and India are much smaller than formal plants. These figures suggest that there are large cross-country differences in terms of firm-growth and firm-size patterns. Hsieh and Klenow (2014) also argue that tax and other institutional differences across countries can explain these patterns. They argue that, in Mexico and India, taxes are higher and are more stringently imposed on large businesses - since small businesses are mostly informal. It is also well-known that enforcement is much looser in developing countries, which allows informal firms to survive. These facts roughly fit the predictions of the model and jointly suggest that the design of government policy might have an important role on entrepreneurial activity as well as firm performance.

\section{Extensions of the Model}

The benchmark model presented in Section 2 produces clear-cut analytical results. But, as always, clarity comes at a cost; the model is based on several simplifying assumptions making the transitional dynamics easier to solve. In this section, I relax some of these assumptions for the purpose of bringing the model closer to reality. Below I argue that, in most cases, the qualitative nature of the benchmark model's results remains unchanged upon relaxing the corresponding assumption.

\subsection{Alternative Tax and Enforcement Settings}

For simplicity, the benchmark model assumes that the tax and enforcement policies can be characterized by two parameters: the tax rate on formal activity, $\tau \in[0,1]$, and the probability 
of getting caught, $\phi \in[0,1]$. The formal entrepreneur always pays the tax $\tau$ per unit of output, whereas the informal entrepreneur pays it only if he gets caught - thus, the effective tax rate under informality is $\phi \tau<\tau$. The tax rate $\tau$ collapses various formal tax items including the corporate income tax, VAT/turnover taxes, public service taxes, and insurances into a single tax variable. Similarly, the enforcement measure collapses several enforcement measures including tax police, mobile tax collectors, computerized detection networks, and additional safety nets into a single enforcement variable. This parsimonious parametrization allows for a clean baseline analysis of the effect of government policy on the extent of informal entrepreneurial activity.

The actual tax and enforcement policies, however, are more complicated and implement additional measures. In this subsection, I emphasize the role of two additional factors: (1) fines and/or asset seizures if caught and (2) the effect of asset size on visibility and, therefore, on the probability of getting caught. These two elements are documented to be crucially important cost items for informal entrepreneurs in addition to standard tax and enforcement measures mentioned above. For example, Djankov, Lieberman, Mukherjee, and Nenova (2002) and OECD (2009) argue - based on evidence from Latin American, Eastern European, and Turkic countries - that the legal treatment of tax evasion and informal activity by authorities have two noteworthy consequences on the operation of informal businesses. ${ }^{14}$ First, informal entrepreneurs are highly vulnerable to getting caught by authorities, because they might lose part or all of their assets - in the form of fines and penalties, if they are "located." Second, the probability of getting caught goes up with asset size; thus, informal entrepreneurs are forced to stay small to minimize their visibility to authorities.

Fines in the form of asset seizures. Suppose that the government imposes a fine on informal entrepreneurs in the form of asset seizures upon getting caught by the authorities. Let $\gamma \in[0,1]$ denote the fraction of assets seized when caught. In this case, the informal entrepreneur pays the effective tax rate of $\phi(\tau+\gamma)$. In some sense, this means that the actual tax paid by the informal entrepreneurs is higher - conditional on being caught - than

\footnotetext{
${ }^{14}$ See also Johnson, Kaufmann, and Shleifer (1997), Johnson, Kaufmann, McMillan, and Woodruff (2000), and Schneider and Enste (2000) for additional evidence and discussion.
} 
the formal tax rate. ${ }^{15}$ Imposing the fine slightly alters the sectoral choice problem. The entrepreneur is indifferent between operating formally and informally if the condition

$$
\theta a_{T}^{\alpha_{f}}(1-\tau)-s=\theta a_{T}^{\alpha_{i}}(1-\phi(\tau+\gamma))
$$

is satisfied. This suggests that

$$
\frac{d a_{T}}{d \gamma}=\frac{-\phi a_{T}^{\alpha_{i}}}{\alpha_{f} a_{T}^{\alpha_{f}-1}(1-\tau)-\alpha_{i} a_{T}^{\alpha_{i}-1}(1-\phi(\tau+\gamma))}<0
$$

which means that the threshold asset level is lower if the fine is increased. In terms of the phase diagram, this suggests that fines operate as enforcement; that is, imposing higher asset seizures on informal entrepreneurs when caught makes the transition easier and has a potential to reduce the magnitude of poverty traps.

Probability of getting caught as a function of the asset size. Suppose now that the enforcement parameter - i.e., the probability of getting caught - is an increasing function of the asset size. To be concrete, I assume $\phi=\bar{\phi} \Phi(a)$ with $\bar{\phi} \in[0,1], \Phi^{\prime}(a)>0, \Phi(0)=0$, and $\Phi(\bar{a})=1$, where $\bar{a}$ is a large, but finite, number. In this formulation, $\bar{\phi}$ captures the actual level of enforcement in the economy as a scale effect and $\Phi(a)$ determines how this enforcement level is reflected on the entrepreneur as a function of the asset size. This extension captures the fact that larger businesses are more visible to authorities and, therefore, staying informal with a large asset size is harder given a certain level of enforcement. In this case, the indifference condition becomes

$$
\theta a_{T}^{\alpha_{f}}(1-\tau)-s=\theta a_{T}^{\alpha_{i}}\left(1-\bar{\phi} \Phi\left(a_{T}\right) \tau\right)
$$

Totally differentiating Equation (4.3) with respect to $a_{T}$ and $\bar{\phi}$ yields the condition that

$$
\frac{d a_{T}}{d \bar{\phi}}=\frac{-\Phi\left(a_{T}\right) \tau a_{T}^{\alpha_{i}}}{\alpha_{f} a_{T}^{\alpha_{f}-1}(1-\tau)+a_{T}^{\alpha_{i}} \bar{\phi} \tau \Phi^{\prime}\left(a_{T}\right)-\alpha_{i} a_{T}^{\alpha_{i}-1}\left(1-\bar{\phi} \Phi\left(a_{T}\right) \tau\right)}<0
$$

\footnotetext{
${ }^{15}$ Note that we need the parametric restriction $\phi(\tau+\gamma)<\tau$ to guarantee that operating in the informal sector is still more attractive. This restriction can be simplified as $\gamma<\tau(1-\phi)$.
} 
Clearly, the qualitative result that stricter enforcement reduces the asset threshold and makes the transition easier also holds in this case. However, there is a nuance; now asset size also has a role in the relationship between the level of enforcement and the asset threshold. Strengthening the level of enforcement in the economy decreases the threshold asset level and this decline further affects $d a_{T} / d \bar{\phi}$ through the additional term $\Phi^{\prime}\left(a_{T}\right)>0$ in the denominator. ${ }^{16}$ To be specific, this term makes it harder to become larger and stay informal; thus, the enforcement policy is even more effective after this extension. ${ }^{17}$

When the enforcement parameter is modeled as a function of asset size, it becomes natural to start thinking about a tax differentiation policy along the size distribution. Since small businesses are less likely to get caught than the large ones, the government may want to provide some additional incentives that would let them switch into formality. These advantages may be in the form of reduced tax rates so that informal entrepreneurs with smaller amount of assets become more likely to operate formally. In fact, empirical studies show that "exemption threshold" type of policies - i.e., businesses below a certain size/revenue threshold being exempt from paying taxes - provide a significant incentive for the small businesses to operate formally. However, these studies also show that such thresholds are an important impediments to the growth of small businesses as they provide incentives to stay small; thus, small businesses become overrepresented along the size distribution and the "missing middle" phenomenon emerges. ${ }^{18}$ Overall, the evidence suggests that providing tax advantages to smaller businesses increases formality rates among them, but may generate impediments to their growth; hence, an important policy trade-off emerges.

Notice that the two extensions discussed above have no effect on the qualitative nature of the results featured by the benchmark model, although there are several interesting nuances that might alter the quantitative predictions. It is clear that the predictions of the benchmark model is quite robust to inclusion of any additional policy measure as long as it mimics the

\footnotetext{
${ }^{16}$ Compare the conditions (2.7) and (4.4) to observe this difference more clearly.

${ }^{17}$ Note that this interaction will also have implications on the dynamic problem. The first order conditions will change, but the nature of the results will remain unaltered.

${ }^{18}$ See, e.g., Besley and Burgess (2004), Guner, Ventura, and Yi (2008), Kleven and Waseem (2013), Krueger (2013), and Hsieh and Olken (2014).
} 
behavior of $\tau$ and/or $\phi .{ }^{19}$ Of course one can think of other public policy interventions that may affect the size of informal sector through other channels - such as the demand side measures that may shift the consumers' attention from informal to formal products. Such extensions, albeit interesting, are out of the scope of this paper.

One important point about the nature of the model's policy setting is that all types of taxes are collapsed into the single tax parameter $\tau$ and all the rest of the policy measures that affect the probability of getting caught is described by the parameter $\phi$. These two assumptions are made for the sake of simplicity and analytical tractability. However, a more complex setting would naturally include different types of taxes, which would have different distortionary effects on the equilibrium outcomes. There are also other public policy elements including general regulation, bureaucracy, property rights, corruption, and public good provision. The paper abstracts from all these different tax and public policy alternatives. When alternative distortionary taxes are included, the model would have the capacity to answer questions about optimal fiscal policy - i.e., the government would choose the optimal tax policy in a Ramsey setting given the optimizing behavior of entrepreneurs [see, e.g., Chari and Kehoe (1999)]. Similarly, the government would also choose $\phi$ to determine the optimal compliance in the informal sector. Then the problem of non-compliance externalities will kick in and complicate the model. Although these are interesting questions and extensions, they are left out for the purpose of focusing on the main transitional forces that the model features.

The model also assumes that there is no borrowing or lending. However, it is well-documented in the literature that businesses relying on internal financial resources grow much slower than the ones with access to external finance [Carpenter and Petersen (2002), Angelini and Generale (2008)]. Having unconstrained access to financial markets is an additional incentive to operate formally and such a borrowing mechanism is not modeled in the paper. Introducing access to finance for formal entrepreneurs would enhance the dual mechanism described in the paper and would provide a more realistic basis for the existence of high-growth transformational businesses. As a consequence, economies with more developed financial systems will likely

\footnotetext{
${ }^{19}$ Notice also that all policy measures may also serve to prevent/reduce future tax evasion, because any cost item also appears in the dynamic problem as part of the present discounted value of output.
} 
have a smaller share of informal businesses at the steady state in comparison to the model with no borrowing and lending, which suggests that the probability of ending up with the formal equilibrium (no poverty case) will be much higher in economies with more developed financial systems.

\subsection{Endogenous Labor Demand}

One of the key assumptions in the benchmark model is that formal sector is more productive than the informal sector, i.e., one unit of physical asset produces a greater amount of final good in the formal sector than in the informal sector. This is an empirically valid idea and is reflected by the assumption $\alpha_{f}>\alpha_{i}$. (See Section 2 for a detailed discussion of empirical validity along with references to relevant work.) The cost structure of the model is such that formal entrepreneurs pay higher taxes than the informal entrepreneurs; thus, operating in the formal sector is more costly. As a result, the main tradeoff in the model is between higher costs versus higher benefits in the formal sector. If costs exceeds benefits, then the entrepreneur chooses to operate informally.

The main purpose of this subsection is to briefly sketch that the assumption $\alpha_{f}>\alpha_{i}$ can be relaxed as $\alpha_{f}=\alpha_{i}=\alpha$ without changing the qualitative predictions of the benchmark model. However, relaxing this assumption requires opening an alternative tradeoff channel for the entrepreneur. To open this alternative channel, I propose relaxing another assumption in the model: the assumption that labor input is fixed - i.e., it is set to 1 - in the production function of the entrepreneur. In this alternative setup, the entrepreneur is, by definition, small, it takes the wage rate as given, and chooses how much labor to hire at each time period. Assume that formal and informal entrepreneurs pay the same wage per unit of work to their employees. This setup necessitates invoking the assumption that probability of getting caught goes up with the asset size. This will be the new tradeoff channel. The intuition is as follows. The production process is homogeneous across sectors.

The informal entrepreneur chooses to use less capital and more labor-because greater capital stock is easier to detect and capital can but labor cannot be seized when caught. The formal 
entrepreneur, on the other hand, can use more physical assets and less labor. Now the sectoral choice depends on the following tradeoff: $(i)$ whether to hire an additional worker and keep the asset size small to minimize the probability of getting caught in exchange for paying lower taxes, $(i i)$ or to expand the business by accumulating greater assets to enjoy greater profits without worrying about higher taxes paid in the formal sector. Similar to the benchmark model, the threshold will depend on the tax and enforcement policies and the initial asset levels will determine who will converge to which equilibrium. The punchline is that it is possible to relax the assumption $\alpha_{f}>\alpha_{i}$ in sensible ways without altering the predictions of the benchmark model.

\subsection{Uncertainty}

It is possible to incorporate into the model aggregate and/or idiosyncratic uncertainty affecting the entrepreneur's decisions. The standard framework to think of such an extension is to make $\theta$ stochastic - simply via a Markovian transition matrix - to capture the cyclical nature of physical capital investments. Using a version of the canonical investment under uncertainty framework with adjustment costs [see Lucas and Prescott (1971)], one can show that uncertainty affects the entrepreneur's expectations on future returns to physical assets. The stationary character of the standard shock structures will let the equilibrium solution to settle down "on average" to a long-run equilibrium or multiple equilibria. Different from the benchmark model, these equilibria depend not only on the government policies and initial wealth positions, but on the distribution of shocks and the structure of adjustment costs. The simulations of this stochastic model will demonstrate the additional result that the threshold variable is counter-cyclical -i.e., it declines (goes up) in good (bad) times making it easier (harder) to transition from informal to formal sector and reducing (magnifying) the size of poverty traps.

Another possibility is to also incorporate a fixed cost of transition to formal sector. This

fixed costs might reflect the costs of tax registration and formal business start-ups. When a combination of uncertainty and fixed costs is in effect, there will be lumpiness in the decision 
to switch from informality to formality, as the entrepreneur will develop an optimal strategy reflecting a $S s$ type of behavior. ${ }^{20}$ To be specific, there will be a period of "inaction" in which the informal entrepreneur will stay on the asset threshold without switching to formality. When the positive shocks accumulate high enough positive returns that overcome the fixed costs, the informal entrepreneur will switch to formality. This time "the switching time to formality" will depend on government policy as well as the other variables mentioned above.

In all these extensions, the qualitative feature of the results will resemble the results produced by the benchmark model. Of course, these models will bring additional insights such as predictions regarding the cyclical nature of poverty traps as well as the state-dependent effect of government policy on entrepreneurial decisions. Moreover, these extensions will help incorporating other policy measures into the model such as capital losses in case of negative shocks and associated loss deductibility policies. Such policies will smooth out the negative impacts of bad shocks and limit the increase in the size of poverty traps in recessions. However, I believe that the costs of mathematical complexity brought in by these extensions will exceed their returns. In particular, it will not be possible to present an analytically tractable transitional dynamics similar to the one presented in Figure (1). Therefore, for the purpose of keeping the model compact and analytically tractable, I ignore presenting the full solution of the stochastic model.

\subsection{Redistribution}

The benchmark model implicitly assumes that government spending is wasteful; that is, the tax revenues collected are not rebated back to the entrepreneurs and, instead, they are spent for some unproductive purpose, i.e., wasted. In this subsection, I relax this assumption by explicitly incorporating a government budget constraint and a simple redistribution scheme into the model.

The benchmark model is basically a microeconomic model-since it describes the behavior of an individual entrepreneur - and aggregation has never been a concern. This simple setup

\footnotetext{
${ }^{20}$ See Stokey (2008) for an excellent review of the models embodying $S$ s type of behavior.
} 
facilitates studying both the steady state and transitional dynamics implications of heterogeneity in the initial asset levels on the main predictions of the model. In a model with a formal redistribution of tax revenues, heterogeneity will enormously limit the analytical tractability of the model since it will be a must to follow what happens to the distribution of assets across entrepreneurs over time. In particular, the threshold asset level $a_{T}$ - the threshold determining the entrepreneur's sectoral choice — will be time-dependent and individual-specific, which will make the transitional dynamics very hard to characterize. In what follows, I will start with the steady state implications of redistribution and then I will sketch out the dynamic elements of the problem as fully as possible.

Suppose that at the steady state, the entrepreneur chooses whether to operate formally versus informally. Different from the benchmark model, the formal entrepreneur receives a lump-sum transfer $L_{s s}$, where the subscript denotes steady state, and the informal entrepreneur does not. The sectoral choice margin is now determined by the equation

$$
\theta a_{T, s s}^{\alpha_{f}}(1-\tau)-s+L_{s s}=\theta a_{T, s s}^{\alpha_{i}}(1-\phi \tau)
$$

Totally differentiating the threshold level $a_{T}$ with respect to $L_{s s}$ gives

$$
\frac{d a_{T, s s}}{d L_{s s}}=\frac{-1}{\alpha_{f} \theta a_{T, s s}^{\alpha_{f}-1}(1-\tau)-\alpha_{i} \theta a_{T, s s}^{\alpha_{i}-1}(1-\phi \tau)}<0
$$

which suggests that introducing redistribution makes the transition from informality to formality easier by reducing the threshold asset level. The main finding of the benchmark model was that the government could reduce poverty traps by reducing taxes on formal activity and strengthening enforcement to prevent informality. The result featured in expression (4.6), by itself, suggests that the government can intervene poverty traps via a third channel: redistribution. An appropriately designed redistribution scheme can provide incentives for less wealth-constrained entrepreneurs to invest more intensively in their businesses and switch to formality.

To sketch off-the-steady-state dynamics, one has to write down the government budget con- 
straint explicitly. Each period, the government collects the tax revenues and redistributes them equally across the formal entrepreneurs in the form of lump-sum transfers $L(t)$. Let $G(t)$ - a cumulative distribution function with finite domain - denote the overall asset distribution in the economy. At each time period, there exists a threshold asset level $a_{T}(t)$ above which the entrepreneurs operate in the formal sector and below which they operate in the informal sector. The government budget constraint can now be written as

$$
\phi \tau \int_{0}^{a_{T}(t)} a(t) d G(t)+\tau \int_{a_{T}(t)}^{\infty} a(t) d[1-G(t)]=\int_{a_{T}(t)}^{\infty} L(t) d[1-G(t)] .
$$

In words, the formal entrepreneur pays the tax and the informal entrepreneur pays only if he gets caught. ${ }^{21}$ The aggregate tax revenues are redistributed back to the formal entrepreneurs only. The complexity here is that we start from a given initial asset distribution $G(0)$ and the economy moves from here to a stationary steady state asset distribution $G_{s s}$. Since $L(t)$ is time dependent in this setup, $a_{T}(t)$ is also time dependent. How $a_{T}(t)$ evolves, in turn, determines how $G(t)$ evolves. Under standard functional form assumptions stated in Lucas and Moll (2014) and invoking convergence rules, the law of motion for $G(t)$ can be formulated explicitly and it can be shown to converge to a steady state asset distribution $G_{s s}$, for which $a_{T, s s}$ and $L_{s s}$ are constant numbers. In particular, the condition

$$
\lim _{t \rightarrow \infty} \dot{a}_{T}(t)=0
$$

must hold to guarantee convergence to a steady-state solution.

It is clear in this exercise that switching from wasteful government spending from a lump-sum redistribution scheme provides incentives to become a formal entrepreneur by reducing the threshold asset level. What is not so clear is the effect of a change in government policy under redistribution. The next point to mention, therefore, is related to the effectiveness of tax and enforcement policy changes under the redistribution regime. Suppose that the tax rate on formal activity is reduced. Reduced taxes will provide an incentive to switch to formality, as

\footnotetext{
${ }^{21}$ This can be interpreted as follows: each period a $\phi$ fraction of informal entrepreneurs are caught and the corresponding amount $\phi \tau$ per unit of output is added on the total tax revenue.
} 
in the benchmark model. However, there might be a competing negative force in the presence of redistribution: if the decline in taxes reduce the tax revenues, then, depending on the elasticities and asset distribution, this may lead to a decline in the lump-sum transfer $L$ and, thus, may provide an indirect disincentive for formality. The net effect of the tax reduction will depend on the relative strengths of these two forces.

An important point to mention is that the functional form of the asset distribution $G$ may affect the extent of these incentives. It is well-documented in the empirical literature that the size distribution of firms is of the Pareto form. ${ }^{22}$ This Pareto form will increase the effectiveness of the redistribution policy, because tax revenues collected from the large firms on the right tail will be less likely to deter formal economic activity; these revenues, in turn, may generate a greater incentive for the small atomistic informal entrepreneurs to switch to formality.

To conclude; an appropriately designed redistribution system will provide incentives for informal entrepreneurs to switch to formality. However, different from the benchmark model, the effectiveness of tax and enforcement policies are more ambiguous under a redistribution scheme; since, the direct effect of a change in tax (or enforcement) policy might be negated by the indirect effect coming from the change in the redistributed amount.

\section{Concluding Remarks}

There is a large shadow economy literature mainly arguing that the share of the informal activity is a function of the tax and enforcement policies. The main idea in this literature is that high taxes on formal production and loose enforcement, which is often the case in LDCs, encourage informal economic activity. My starting point also rests on this idea; that is, I start with a model in which entrepreneurs choose whether to operate in the formal versus informal sectors. The sectoral choice problem is a function of tax and enforcement policies, consistent with the literature.

\footnotetext{
${ }^{22}$ See, for example, Simon and Bonini (1958), Ijiri and Simon (1964), Axtell (2001), and Luttmer (2007).
} 
The novelty that this paper introduces is the idea that the interaction between wealth constraints and government policy jointly determines the fraction of entrepreneurs entrapped in the informal economy forever. When taxes are high and enforcement is loose, initially constrained entrepreneurs choose to operate informally, they have no incentives to make expansionary investments in their businesses because formal activity is costly, and, as a result, they stay small and operate informally in the long run. This is literally a poverty trap. The main insight in this paper is that poverty traps are related to government policy and, therefore, can be reduced in magnitude. To be precise, I show that lowering taxes over formal production and tightening enforcement will reduce the magnitude of poverty traps and encourage entrepreneurs to become large businesses operating in the formal economy in the long run.

This paper is also related to the literature studying the link between wealth constraints and entrepreneurship. That entrepreneurs are constrained by their initial wealth levels is a common finding in the literature. I show that, given an initial wealth level, whether an entrepreneur can transition into formal economy or trapped in the informal economy depends on government policy; that is, government policy is the mediating force determining whether initially constrained informal entrepreneurs can expand their businesses and turn into formal enterprises or not. The main policy implication of these results is that governments should decrease taxes on formal production and increase enforcement levels, if they want to combat informality and reduce the magnitude of poverty traps.

I also show that introducing an appropriately designed redistribution system may serve as a third policy mechanism - besides reducing taxes and strengthening enforcement - to encourage formal entrepreneurship. One caveat, however, is that the effect of tax and enforcement policies on informality becomes more ambiguous when they are implemented under a lumpsum redistribution system. There will be a direct effect of a tax cut on providing incentives for formal production, just as in the benchmark model. There will also be an indirect effect of the tax cut on the redistributed amount. If the amount of the lump-sum transfer goes down as a response to the tax cut, then the sign of this indirect effect will depend on the relevant elasticities and the overall distribution of assets in the economy. This ambiguity calls 
for additional research about the effect of government policy on informal economic activity when a redistribution scheme is in effect. 


\section{References}

Amaral, P. And E. Quintin (2006): "A Competitive Model of the Informal Sector," Journal of Monetary Economics, 53, 1541-1553.

Angelini, P. And A. Generale (2008): "On the Evolution of Firm Size Distributions," American Economic Review, 98, 426-438.

Axtell, R. L. (2001): "Zipf Distribution of U.S. Firm Sizes," Science, 293, 1818-1820.

Ayyagari, M., T. Beck, And A. Demirguc-Kunt (2007): "Small and Medium Enterprises across the Globe," Small Business Economics, 29, 415-434.

AzARiadis, C. (1996): "The Economics of Poverty Traps Part One: Complete Markets," Journal of Economic Growth, 1, 449-486.

BanerJee, A. V. (2004): "Contracting Constraints, Credit Markets and Economic Development," in Advances in Economics and Econometrics: Theory and Applications, ed. by M. Dewatripont, L. P. Hansen, and S. J. Turnovsky, Cambridge, UK: Cambridge University Press, vol. III, chap. 1, 1-46.

Banerjee, A. V. And A. F. Newman (1993): "Occupational Choice and the Process of Development," Journal of Political Economy, 101, 274-298.

Benabou, R. J. (1993): "Workings of a City: Location, Education, and Production," Quarterly Journal of Economics, 108, 619-652.

Besley, T. J. And R. Burgess (2004): "Can Labor Regulations Hinder Economic Performance? Evidence from India," Quarterly Journal of Economics, 119, 91-134.

Blanchflower, D. And A. J. Oswald (1998): "What Makes An Entrepreneur?" Journal of Labor Economics, 16, 26-60.

Boadway, R., M. Marchand, and P. Pestieau (1991): "Optimal Linear Income Taxation in Models with Occupational Choice," Journal of Public Economics, 46, 133-162. 
Buera, F. J. (2008): "Persistency of Poverty, Financial Frictions, and Entrepreneurship," Unpublished manuscript, Northwestern University.

Cagetti, M. And M. De Nardi (2009): "Estate Taxation, Entrepreneurship, and Wealth," American Economic Review, 99, 85-111.

Carpenter, R. E. And B. C. Petersen (2002): "Is the Growth of Small Firms Constrained by Internal Finance?" Review of Economics and Statistics, 84, 298-309.

Chari, V. V. And P. J. Kehoe (1999): "Optimal Fiscal and Monetary Policy," in Handbook of Macroeconomics, ed. by K. J. Arrow and M. D. Intriligator, Elsevier, vol. 1, chap. 26, 1671-1745.

Cooper, R. W. And J. C. Haltiwanger (2006): "On the Nature of Capital Adjustment Costs," Review of Economic Studies, 73, 611-633.

Cullen, J. B. And R. H. Gordon (2007): "Taxes and Entrepreneurial Risk-Taking: Theory and Evidence for the U.S." Journal of Public Economics, 91, 1479-1505.

DE MezA, D. (2002): "Overlending?" Economic Journal, 117, F17-F31.

De Meza, D. And C. Southey (1996): "The Borrower's Curse: Optimism, Finance, and Entrepreneurship," Economic Journal, 106, 375-386.

De Paula, A. And J. A. Scheinkman (2011): "The Informal Sector: An Equilibrium Model and Some Empirical Evidence from Brazil," Review of Income and Wealth, 57, S8S26.

De Soto, H. (1989): The Other Path: The Invisible Revolution in the Third World, New York, NY: Harper and Row.

(2000): The Mystery of Capital: Why Capitalism Triumphs in the West and Fails Everywhere Else, New York, NY: Basic Books.

Decker, R., J. C. Haltiwanger, R. Jarmin, And J. Miranda (2014): "The Role of Entrepreneurship in US Job Creation and Economic Dynamism," Journal of Economic Perspectives, 28, 3-24. 
Djankov, S., I. Lieberman, J. Mukherjee, and T. Nenova (2002): "Going Informal: Benefits and Costs," Unpublished manuscript, World Bank.

Durlauf, S. N. (1993): "Nonergodic Economic Growth," Review of Economic Studies, 60, 349-366.

(1996): "A Theory of Persistent Income Inequality," Journal of Economic Growth, 1, 75-93.

Evans, D. S. And B. Jovanovic (1989): "An Estimated Model of Entrepreneurial Choice under Liquidity Constraints," Journal of Political Economy, 97, 808-827.

FARrell, D. (2004): "The Hidden Dangers of the Informal Economy," McKinsey Quarterly, $3,26-37$.

Fossen, F. M. And D. Rostam-Afschar (2012): "Precautionary and Entrepreneurial Savings: New Evidence from German Households," Oxford Bulletin of Economics and Statistics, $75,528-555$.

Friedman, E., S. Johnson, D. Kaufmann, D., And P. Zoido-Lobaton (2000): "Dodging the Grabbing Hand: The Determinants of Unofficial Activity in 69 Countries," Journal of Public Economics, 76, 459-493.

Galor, O. and H. E. Ryder (1989): "Existence, Uniqueness, and Stability of Equilibrium in an Overlapping-Generations Model with Productive Capital," Journal of Economic Theory, 49, 360-375.

Galor, O. And J. Zeira (1993): "Income Distribution and Macroeconomics," Review of Economic Studies, 60, 35-52.

Gentry, W. M. and R. G. Hubbard (2004): "Entrepreneurship and Household Saving," The B.E. Journal of Economic Analysis 83 Policy, 4, 1-55.

Gordon, R. H. (1998): "Can High Personal Tax Rates Encourage Entrepreneurial Activity?" IMF Staff Papers, 45, 49-80. 
Guner, N., G. Ventura, And X. Yi (2008): "Macroeconomic Implications of SizeDependent Policies," Review of Economic Dynamics, 11, 721-744.

Haltiwanger, J. C. (2012): "Job Creation and Firm Dynamics in the U.S." in Innovation Policy and the Economy, ed. by J. Lerner and S. Stern, University of Chicago Press, NBER Book Series, 17-38.

Haltiwanger, J. C., R. Jarmin, And J. Miranda (2013): "Who Creates Jobs? Small vs Large vs Young," Review of Economics and Statistics, 95, 347-361.

Holtz-Eakin, D., D. Joulfaian, And H. S. Rosen (1994): "Sticking It Out: Entrepreneurial Survival and Liquidity Constraints," Journal of Political Economy, 102, 53-75.

Hsien, C.-T. And P. J. Klenow (2014): "The Life Cycle of Plants in India and Mexico," Quarterly Journal of Economics, 129, 1035-1084.

Hsieh, C.-T. And B. A. Olken (2014): "The Missing "Missing Middle"," Journal of Economic Perspectives, 28, 89-108.

Hubbard, G. And W. M. Gentry (2000): "Tax Policy and Entrepreneurial Entry," American Economic Review, 90, 283-287.

— (2005): “Success Taxes,' Entrepreneurial Entry, and Innovation," in Innovation Policy and the Economy, ed. by A. B. Jaffe, J. Lerner, and S. Stern, MIT Press, vol. 5, 87-108.

Hurst, E. And A. Lusardi (2004): "Liquidity Constraints, Household Wealth, and Entrepreneurship," Journal of Political Economy, 112, 319-347.

Ihrig, J. And K. S. Moe (2004): "Lurking in the Shadows: The Informal Sector and Government Policy," Journal of Development Economics, 73, 541-557.

IJIRI, Y. AND H. A. Simon (1964): "Business Firm Growth and Size," American Economic Review, 54, 77-89.

IMF (2016): "Acting Now, Acting Together," . 
Johnson, S., D. Kaufmann, J. McMillan, and C. Woodruff (2000): "Why Do Firms Hide? Bribes and Unofficial Activity After Communism," Journal of Public Economics, 76, $495-520$.

Johnson, S., D. Kaufmann, And A. Shleifer (1997): "The Unofficial Economy in Transition," Brookings Papers on Economic Activity, 28, 159-240.

Johnson, S., D. Kaufmann, And P. Zoido-Lobaton (1998): "Regulatory Discretion and the Unofficial Economy," American Economic Review Papers \& Proceedings, 88, 387-392.

Jones, C. I. (2008): "Comment on La Porta and Shleifer "The Unofficial Economy and Economic Development"," Brookings Papers on Economic Activity, 39, 353-359.

Kanbur, S. M. (1981): "Risk Taking and Taxation: An Alternative Perspective," Journal of Public Economics, 15, 163-184.

KerR, W. R. AND R. NAndA (2011): "Financing Constraints and Entrepreneurship," in Handbook of Research on Innovation and Entrepreneurship, ed. by D. Audretsch, O. Falck, and S. Heblich, Cheltenham, UK: Edward Elgar Publishing, 88-103.

Kleven, H. J. And M. Waseem (2013): "Using Notches to Uncover Optimization Frictions and Structural Elasticities: Theory and Evidence from Pakistan," Quarterly Journal of Economics, 128, 669-723.

Krueger, A. O. (2013): "The Missing Middle," in Economic Reform in India: Challenges, Prospects, and Lessons, ed. by N. C. Hope, A. Kochar, R. Noll, and T. N. Srinivasan, Cambridge University Press, chap. 9.

La Porta, R. And A. Shleifer (2008): "The Unofficial Economy and Economic Development," Brookings Papers on Economic Activity, 39, 275-363.

(2014): "Informality and Development," Journal of Economic Perspectives, 28, 109126.

Li, W. (2002): "Entrepreneurship and Government Subsidies: A General Equilibrium Analysis," Journal of Economic Dynamics and Control, 26, 1815-1844. 
Lindh, T. And H. Ohlsson (1998): "Self-Employment and Wealth Inequality," Review of Income and Wealth, 44, 25-42.

LoAyza, N. V. (1996): "The Economics of the Informal Sector: A Simple Model and Some Empirical Evidence from Latin America," Carnegie Rochester Conference Series on Public Policy, 45, 129-162.

Lucas, R. E. J. And B. Moll (2014): "Knowledge Growth and the Allocation of Time," Journal of Political Economy, 122, 1-51.

Lucas, R. E. J. and E. C. Prescott (1971): "Investment Under Uncertainty," Econometrica, 39, 659-681.

Luttmer, E. G. J. (2007): "Selection, Growth, and the Size Distribution of Firms," Quarterly Journal of Economics, 122, 1103-1144.

McKenzie, D. J. And C. Woodruff (2006): "Do Entry Costs Provide an Empirical Basis for Poverty Traps? Evidence from Mexican Microenterprises," Economic Development and Cultural Change, 55, 3-42.

MCKinsey (1998): "Productivity - The Key to An Accelerated Development Path in Brazil," McKinsey Global Institute Country Report.

MookherJee, D. And D. RAJ (2002): "Contractual Structure and Wealth Accumulation," American Economic Review, 92, 818-849.

Murphy, K. M., A. Shleifer, And R. W. Vishny (1989): "Income Distribution, Market Size, and Industrialization," Quarterly Journal of Economics, 104, 537-564.

NANDA, R. (2010): "Entrepreneurship and the Discipline of External Finance," Unpublished manuscript, Harvard University.

OECD (2009): "Competition Policy and the Informal Economy," Policy Roundtable.

Peck, R. M. (1989): "Taxation, Risk, and Returns to Scale," Journal of Public Economics, 40, 319-330. 
Quadrini, V. (2000): "Entrepreneurship, Saving, and Social Mobility," Review of Economic Dynamics, 3, 1-40.

RAUCH, J. E. (1991): "Modeling the Informal Sector Formally," Journal of Development Economics, 35, 33-48.

Schneider, F., A. Buehn, And C. E. Montenegro (2010): "New Estimates for the Shadow Economies all over the World," International Economic Journal, 24, 443-461.

Schneider, F. G. And D. H. Enste (2000): "Shadow Economies: Size, Causes, and Consequences," Journal of Economic Literature, 38, 77-114.

SchoAR, A. (2010): "The Divide between Subsistence and Transformational Entrepreneurship," in Innovation Policy and the Economy, ed. by J. Lerner and S. Stern, University of Chicago Press, vol. 10 of NBER Book Series, 57-81.

Simon, H. A. And C. P. Bonini (1958): "The Size Distribution of Business Firms," American Economic Review, 48, 607-617.

Stokey, N. L. (2008): The Economics of Inaction: Stochastic Control Models with Fixed Costs, Princeton, NJ: Princeton University Press.

Thomas, J. J. (1992): Informal Economic Activity, Ann Arbor, MI: University of Michigan Press.

Tumen, S. (2016): "Informality as a Stepping Stone: A Search-Theoretical Assessment of Informal Sector and Government Policy," Central Bank Review, 16, 109-117.

WorldBank (2005): "Investment Climate Assessment: Brazil," Country Background Report. 

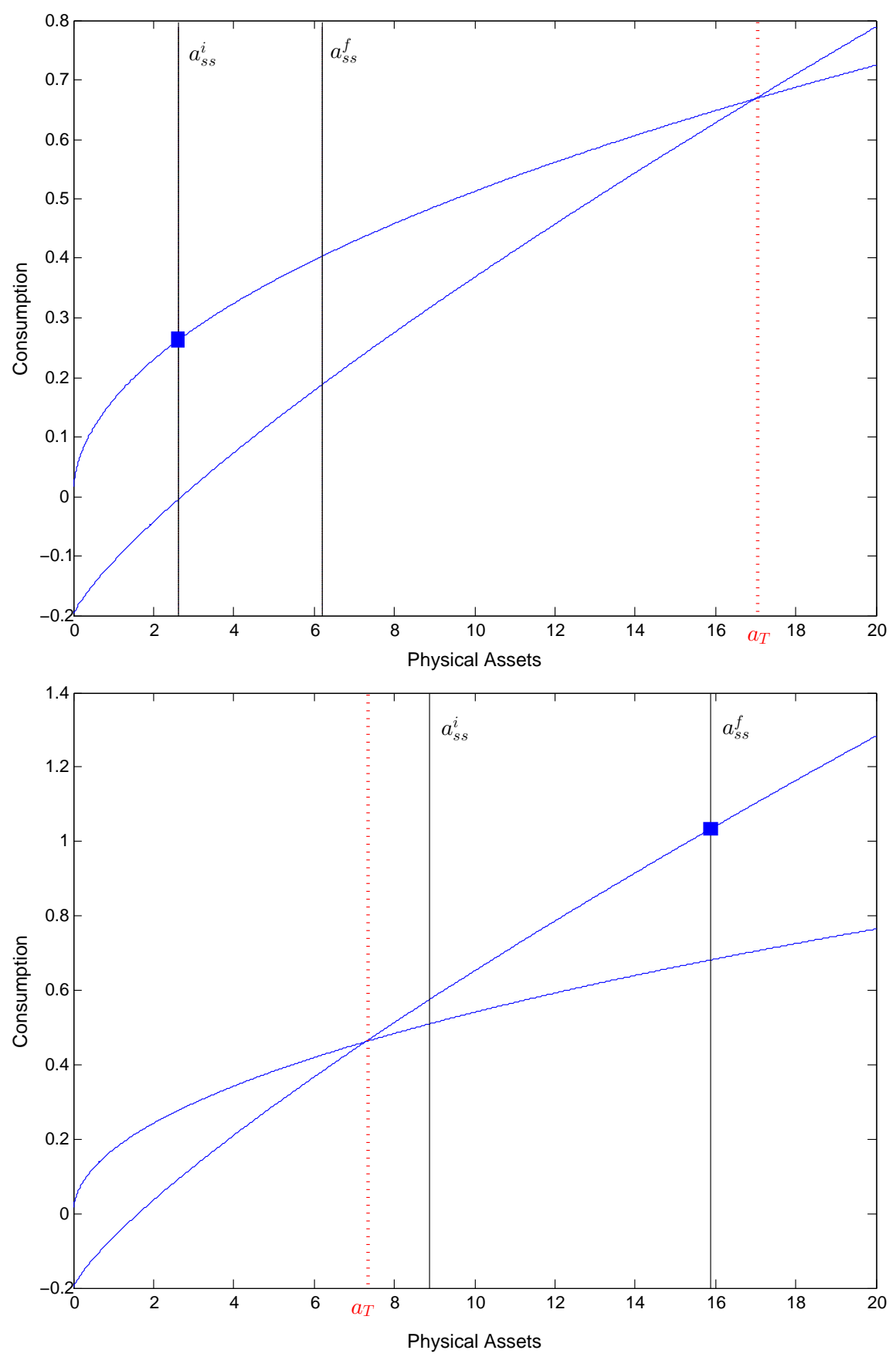

Figure 3: CASES FOR UNIQUE LONG-RUN EQUILIBRIUM. I use the same parameter configuration as the one proposed in Figure (2). The difference is that the tax rate is no more 0.4; it is increased to 0.5 on the upper panel and decreased to 0.3 on the lower panel. 